\title{
The need for speed in a crisis discipline: perspectives on peer-review duration and implications for conservation science
}

\author{
Steven J. Cooke ${ }^{1,2, *}$, Vivian M. Nguyen ${ }^{1}$, Alexander D. M. Wilson ${ }^{1,2,3}$, \\ Michael R. Donaldson ${ }^{1}$, Austin J. Gallagher ${ }^{1,4}$, Neil Hammerschlag ${ }^{4,5}$, \\ Neal R. Haddaway ${ }^{6}$
}

${ }^{1}$ Fish Ecology and Conservation Physiology Laboratory, Department of Biology, Carleton University, 1125 Colonel By Dr., Ottawa, ON K1S 5B6, Canada

${ }^{2}$ Canadian Centre for Evidence-Based Conservation and Environmental Management, Institute of Environmental Science, Carleton University, Ottawa, ON K1S 5B6, Canada

${ }^{3}$ School of Life and Environmental Sciences, Deakin University, Burwood, Victoria 3125, Australia

${ }^{4}$ Shark Research and Conservation Program, University of Miami, 4600 Rickenbacker Causeway, Miami, FL 33149, USA

${ }^{5}$ Abess Center for Ecosystem Science and Policy, University of Miami, 1365 Memorial Drive, Miami, FL 33146, USA

${ }^{6}$ Mistra Council for Evidence-based Environmental Management, Royal Swedish Academy of Sciences, 10405 Stockholm, Sweden

\begin{abstract}
Scholarly peer review relies on rigorous yet fair assessments of articles by qualified referees in a timely manner. We considered the extent to which a prolonged peer-review process can delay the dissemination of results in a conservation context by combining insight from a survey with our own perspectives. A survey of authors who published peer-reviewed articles in biodiversity and conservation in 2012 and 2013 yielded 461 responses from participants in 119 countries. Approximately $44 \%$ of respondents thought that slow review times might hamper conservation, while only $\sim 5 \%$ provided specific examples of how slow reviews had actually impeded conservation actions or policy formation. When queried about the value of expediting the review process for studies of high policy or conservation relevance, ca. 1/3 of respondents thought it was a worthwhile idea in principle, though mechanics of implementing such practices are unclear. Author self-identification of potentially important papers could lead to requesting a rapid review provided that a paper meets certain criteria - an approach already used by some generalist journals. Given the urgency of many conservation-oriented initiatives, we encourage the entire editorial team (staff, editors, referees, authors) to make a concerted effort towards improving the speed of the peer-review process while maintaining quality. Such efforts would reflect the notion that timeliness is a key component of scientific relevance to practitioners and policy makers in a crisis discipline. We conclude that there is a 'need for speed' and advocate that rapid, rigorous and thorough peer review can be accomplished and can provide collective benefits to the scientific community and global biodiversity.
\end{abstract}

KEY WORDS: Peer review - Conservation - Scientific publishing · Biodiversity - Science communication $\cdot$ Science dissemination $\cdot$ Journal editor $\cdot$ Referee 


\section{INTRODUCTION}

For better or worse, peer-reviewed journals are the primary means by which conservation scientists disseminate their work (Arlettaz et al. 2010, McKinley et al. 2012, Cook et al. 2013, Habel et al. 2013, Hulme 2014). Science clearly has a critical role in conservation (Tracy \& Brussard 1996, Gibbons et al. 2011, Habel et al. 2013), and peer-reviewed literature is an important but flawed tool for closing the knowledge-action gap (Knight et al. 2008, Hulme 2014). In the realm of conservation science, available research is often limited because of the conservation status of a species (e.g. being endangered) or the rapid development of crises (e.g. oil spills), making systemic reviews impossible (Pullin \& Stewart 2006). In these circumstances, a single research study has the potential to have a significant influence on the conservation community (e.g. by identifying environmental threats and assisting with the recovery of an imperiled population) such that rapid dissemination of conservation-oriented papers would seem important (Walsh et al. 2015).

Even in the electronic age, the publication process can take months or even years from submission to publication, often due, in large part, to delays in finding and securing reviewers as well as conducting the reviews. The peer-review process is essential to vet research for quality and validity, and while the process should not be rushed, it is nonetheless important to consider whether elements of a prolonged publication process impede timely conservation action (e.g. O'Donnell et al. 2010). The submission process is now 'immediate', as authors submit papers online rather than waiting for printed paper versions to make their way through the mail system, as was still common as recently as 10 years ago. Similarly, when a paper is accepted, many journals post the 'early access' version online within days of receiving corrected proofs. Early access papers receive a Digital Object Identifier and as such may be cited prior to final formatting and assignment of volume, issue and page numbers. However, one phase of the publication process has not yet changed, viz. our collective dependence on the goodwill of referees to provide rigorous yet fair assessments of submitted articles in a timely manner (Rowland 2002). Indeed, most reviewers are volunteers. Some reviewers are quick and diligent, while others are slow or simply fail to submit their review after initially accepting the task, leading to further delays when editors must seek out alternative referees.
Do slow review times actually affect conservation practice? What do conservation authors think? What are their experiences? In a 'crisis discipline' such as conservation science (Soulé 1985), we would presume that lack of information due to slow review processes would have consequences for conservation practice. Here, we explored the extent to which the peer-review process, in particular lengthy processes, may hinder the dissemination of timely sciencebased conservation knowledge from the authors' perspective. This is particularly important in an era of human-induced rapid environmental change and regulatory bodies that require this information in order to respond with effective conservation strategies. We highlight some consequences of lengthy reviews on conservation policy and outcomes with hopes to identify possible opportunities for improving the peer-review system for mission-oriented (Meine et al. 2006) and time-sensitive disciplines such as conservation science. To do so, we surveyed authors of a representative subset of peer-reviewed papers in the realm of 'conservation biology' and combined that information with our own perspectives on the topic.

\section{METHODS}

This study is an independent sub-component of a broader study (Nguyen et al. 2015) investigating author experiences with peer review and the factors that influence their identification of optimal review durations. E-mail addresses were extracted from citation records searched within Web of Science (consisting of Web of Science Core Collections, Biosis Previews [subscription up to 2008], MEDLINE, SciELo and Zoological Records) on 9 April 2014. The search string 'conservation AND *diversity' was used, and search results were restricted to 2013 (to ensure that authors were still active), and the search results were further refined to include subject categories: environmental sciences ecology, biodiversity conservation, zoology, plant sciences, marine freshwater biology, agriculture, forestry, entomology and fisheries. A total of 4606 individual email addresses were extracted out of 6142 results to make up our mailing list. E-mail invitations were sent to each author to participate in the online questionnaire hosted on Fluid Surveys. Of these e-mail addresses, 312 were no longer active or non-functional. E-mails that were returned with an indication of an e-mail address change were sent an invitation to their new address. We sent an additional invita- 
tion on 22 May 2014 using a mailing list produced from an additional extraction of 2679 e-mail addresses within results of another search using the above string and subject categories but restricted to 2012. In this instance, 426 addresses were non-functional or no longer active. Reminders were sent between 18 and 20 June 2014, and we closed access to the questionnaire on 3 July 2014. The questionnaire was pre-tested with 5 authors and approved by the Carleton University Research Ethics Board (100958).

The entire questionnaire was composed of 38 openand closed-ended questions (as part of a broader study), of which 3 of the open-ended and 2 closedended questions were relevant to the objectives of this paper, not including characteristics of the surveyed authors (i.e. gender, age, employment, country, publishing experience). Questions relevant to this study included:

(1) Do you believe there are consequences of manuscript review for your field in conservation science? Response options: (a) Yes, (b) No, (c) Provide examples if you have them.

(2) Do you think the review process should be altered to change review time? Response options for each of these questions: (a) Yes, (b) No, (c) No opinion, (d) Prefer not to answer, (e) if Yes, explain how.

(3) Do you think the review process should be altered if the results have high conservation implications? Policy implications? Potential for public interest or media attention? High scientific significance for advancing the field of study? Response options for each of these questions: (a) Yes, (b) No, (c) Neither, (d) No opinion, (e) Prefer not to answer

(4) If Yes to any of the questions in (3), should it be: Faster? Slower?

(5) Are you aware of any instances in which a 'lengthy' peer review had marked effects on a conservation problem/issue? If yes, please describe.

Open-ended responses were imported into NVivo 10 to detect patterns in responses using descriptive coding, which assigns labels to data to summarize the data into themes or words (Miles et al. 2014). This method enables the researchers to quantify the proportion of responses that are in agreement with emerging themes. There are certain caveats and biases when dealing with responses from online questionnaires, and we do not claim that the recorded responses are representative of all authors working in conservation and biodiversity, but we believe it reflects insights to instances when lengthy peer-review processes can delay or hinder conservation practices.

\section{RESULTS}

\section{Response rate and overall respondent characteristics}

Of all the invited participants ( $\mathrm{N}=6547)$, we received 673 responses, of which 461 completed the survey in its entirety although they were able to skip some questions without answering. Of the completed responses, $28 \%$ came from females and $63 \%$ were from males ( $<1 \%$ preferred not to say). The majority of respondents were in the age category 31-40 yr old (38.2\%), followed by 41-50 yr (24\%), 51-64 yr (18\%), $21-30 \mathrm{yr}(11 \%), \geq 65 \mathrm{yr}(<5 \%)$ and $<1 \%$ for those under 21 yr old (2 respondents), indicating a response bias towards more established authors and fewer early-career perspectives. Approximately half of the respondents authored $>20$ publications (including $21 \%$ of 623 responses with $>50$ publications), and only $10 \%$ with $<10$ publications. We received responses from 119 different countries and categorized the countries based on economic income set out by the World Bank (2014) http://data.worldbank.org/ about/country-and-lending-groups. The majority of respondents $(\mathrm{N}=640)$ worked in countries of high-income economies $(78 \%)$, followed by upper-middleincome economies (17\%), lower-middle-income $(4 \%)$, and $<2 \%$ low-income economies. The top countries participating in this study included the USA (17\%), the UK (10\%), Australia (8\%) and Brazil (7\%). Respondents from academic professionals made up the majority of respondents (378 of $611 ; 59 \%$ ), followed by graduate students (14\%) and professionals with government agencies (11\%), non-government or non-profit organizations $(9 \%)$ and the private sector $(2 \%)$. Overall, the perspectives presented in this study are biased toward experienced male academics from higher-economic-income regions. Note that not all participants responded to every question, and thus sample size varied with every question asked.

\section{Respondents' opinions on perceived consequences of review duration to conservation science}

We queried respondents on the consequences of manuscript review duration for the field of conservation science. Opinions were relatively evenly divided; $56 \%$ (of $\mathrm{N}=455$ ) of respondents considered that there were no consequences of slow reviews for conservation science, whereas $44 \%$ thought that there were consequences. In this particular sample, 'slow' review times were reported to be on average $32 \mathrm{wk}$, with the opinion of 'slow' averaging $14 \mathrm{wk}$ 
(Nguyen et al. 2015). Of the open-ended responses gathering opinions of review duration for conservation science, the majority of respondents indicated potential consequences for policy making and management implications (63 of 134 useable responses), particularly regarding debates and discussions surrounding species at risk, development projects and protected areas. Representative perspectives (note that we could not control for policy expertise or naiveté) included:

In some cases, agencies, NGOs or industry use peerreviewed information to justify management decisions, and it makes a BIG difference if it is published or not. Policy and management decisions usually cannot wait, and sometimes these decisions can have long-lasting and/or irreversible consequences. Having the timely support of published papers to support/guide these decisions can be very important, and can contribute to maintain the 'good' reputation of scientists. (male, 31-40 yr, Australia)

When changes to policy/practice are occurring in the field (i.e. when people are already starting to manage animals differently), and these changes are being pushed through for socio-political reasons, and your manuscript provides information necessary to improve animal management, then holding up the manuscript in review means that animals are managed to a lower standard than what they could be if your manuscript was published earlier. In the case of threatened fauna management, a slow review process can literally mean serious outcomes for the prospects of threatened fauna population. (male, 31-40 yr, Australia)

In addition, respondents (20 of 138) indicated that slow reviews may affect areas of policy and management because of insufficient evidence when manuscripts are still in review during discussions or debate of a topic. The findings supporting these major topics become outdated and no longer relevant when the review duration is too lengthy.

I have a paper that took almost 2 years to get published (fault of the authors and editorial process). In the meantime, any kind of policy it could have influenced has probably been discussed in other forums. Not only did the paper lose its importance but the Journal lost the opportunity to influence environmental decision making. (male, 51-64 yr, location unknown)

Since, in many cases, conservation biology is all about emerging issues and acting fast, a slow review may have consequences on how updated a piece of information is.

The information can be out of date or no longer relevant, as conservation has a lot of issues that are timely and where active engagement is critical for success. (female, 41-50 yr, UK)

A number of respondents expressed their concern that conservation is a field of 'urgency', and that slow review times have a number of implications:
Animals and systems that are at risk cannot afford slow review times. The world and extinction risk are not slowing down. Animals are still being poached and finned while my paper, which could improve biodiversity and policy, is sitting on someone's desk. This is a real problem. (male, 21-30 yr, South Africa)

There are urgent measures to take or to share in order to change environmental policies. For example, recently we propose [sic] a change of the capture size of the queen conch in the Caribbean region. To propose a change in the Mexican fisheries we needed the scientific research or reference published. (female, 41-50 yr, Mexico)

Delayed publication can either slow implementation of relevant conservation strategies, and/or prevents awareness of research findings. While it is always good to replicate science, with limited research dollars, it often seems wasteful to have someone else conduct research in a very similar vein when other conservation questions could be addressed. If publication of conservation is delayed, there is greater risk of this, I suspect. (male, $31-40$ yr, USA)

These examples suggest that timing and the availability of information is everything in conservation, and rapid publication is the key. We affirm that strong data and robust research never have an expiration date, but that certain data can be used strategically to inform conservation measures which otherwise occur rarely (e.g. every few years, once per decade etc.) or sporadically, annually or bi-annually (i.e. species reviews for Endangered Species Acts listing, threat assessment, stock assessment).

\section{Examples of consequences of long peer review for actual conservation issues}

Of the completed responses $(\mathrm{N}=454), \sim 5 \%$ of the respondents were aware of instances where a lengthy peer review had marked effects on an actual conservation issue, particularly when involved in court cases, assessment and listing of endangered species, management plans, assessment reports (e.g. Intergovernmental Panel on Climate Change assessment reports), policy meetings/discussions/briefings, and protected areas:

Review of a paper I was co-author on was delayed by a reviewer until after a major conservation policy implementation program had been finalized, with the implied intent of ensuring our research findings were not considered as part of that program. (male, 51-64 yr, Australia)

I had a paper on a shark species that has significant policy implications at a time when this species was being proposed for listing on the Endangered Species List. I had to wait over a year to get it published due to slow reviews...it could have seriously affected our chance to change policy for imperiled species. (male, 21-30 yr, South Africa) 
Lengthy reviews of species descriptions have prevented taxa from being included in conservation and management plans. (male, 41-50 yr, USA)

I have a paper to be published on the conflict between bears and hunting regimes. The delay experienced due to a poor review process means that the paper cannot be used to draft a conservation plan for the species. (male, $31-40$ yr, Italy)

\section{Should the review process be altered?}

When asked about whether to alter the review process if the results have high scientific significance for advancing the field of study, $35 \%$ of respondents said 'yes', of whom $92 \%$ stated it should be faster (Table 1). When asked whether the review process should be altered if the results have high conservation implications (Table 1), those respondents who said 'yes' $(40 \%)$ agreed that the review time should be faster (96\%). If the scientific results have high policy implications, 35\% (of $\mathrm{N}=459$ ) of respondents thought the review time should also be faster $(94 \%$ of 159), whereas $49 \%$ did not think the review time should be altered, and $<10 \%$ did not have an opinion or thought neither, respectively. A slightly higher proportion of respondents $(60 \%$ of 459$)$ did not believe the review time should be altered for any results that had potential public or media interest, and $24 \%$ of those who said 'yes' believed it should be faster (Table 1).

\section{Synthesis}

Almost half of the respondents believed long peerreview durations have the capacity to impact conservation science outcomes (Table 2). Conversely, over half of the surveyed authors did not believe that delayed peer-review times have an impact on conservation science. It seems counterintuitive that delaying information would not impede or affect effective conservation or decision making. Perhaps it reflects the current lack of information or evidence that has been used in policy and practice, as this respondent discussed:

A very slow review may limit the publication of important policy or scientific findings. However, that delay is often trivial - how often does an extra 4-8 weeks of 'review' influence the actions of government and the public? In all honesty most of our science has very little influence on conservation decision making. Thus, a delay will have personal consequences for the authors, but likely little consequence for the public. (male, 41-50 yr, Canada)

Indeed, reports have indicated that evidence is often not used. For example, $71 \%$ of management plans from major conservation organizations within

Table 1. Respondents' perspectives on alteration of the review process based on a number of factors and direction of alteration, shown in frequency of responses (\%). N: sample size

\begin{tabular}{|c|c|c|c|c|c|c|c|}
\hline Should the review process be altered if results have... & No & Neither & Yes & $\begin{array}{l}\text { No } \\
\text { opinion }\end{array}$ & $\begin{array}{c}\text { Prefer } \\
\text { not }\end{array}$ & $\begin{array}{l}\text { If 'yes', it } \\
\text { Faster }\end{array}$ & $\begin{array}{l}\text { hould be: } \\
\text { Slower }\end{array}$ \\
\hline $\begin{array}{l}\text { High scientific significance for advancing } \\
\text { field of study? }(\mathrm{N}=459)\end{array}$ & 51 & 6 & 35 & 8 & $<1$ & 92 & 8 \\
\hline High conservation implications? $(\mathrm{N}=460)$ & 51 & 9 & 40 & 0 & 0 & 96 & 4 \\
\hline High policy implications? $(\mathrm{N}=459)$ & 49 & 6 & 35 & 8 & $<1$ & 94 & 6 \\
\hline High public and media interest? $(\mathrm{N}=459)$ & 41 & 6 & 24 & 7 & $<1$ & 96 & 4 \\
\hline
\end{tabular}

Table 2. Frequency (\%) of respondents' perspectives on whether scientific significance for advancing the field of study ( $\mathrm{N}=$ $461)$, conservation implications of results $(\mathrm{N}=208)$ and policy implications of results $(\mathrm{N}=456)$ account for the duration of a review process, and the average score (mode and median) of the 5-point Likert-type scale (results from a broader study by Nguyen et al. 2015)

\begin{tabular}{|lcccccc|}
\hline & $\begin{array}{c}\text { Greatly } \\
\text { slows } \\
\text { review speed }\end{array}$ & $\begin{array}{c}\text { Somewhat } \\
\text { slows } \\
\text { review speed }\end{array}$ & $\begin{array}{c}\text { No } \\
\text { impact }\end{array}$ & $\begin{array}{c}\text { Somewhat } \\
\text { speeds up } \\
\text { review }\end{array}$ & $\begin{array}{c}\text { Greatly } \\
\text { speeds up } \\
\text { review }\end{array}$ & Mode \\
\hline Scientific significance & 1 & 10 & 46 & 34 & 9 & 3 \\
Conservation implications & 1 & 5 & 74 & 17 & 3 & 3 \\
Policy implications & 2 & 10 & 72 & 14 & 3 & 3 \\
\hline
\end{tabular}


the UK are based on traditional management techniques that have been used for thousands of years and are based on anecdote or opinion, and not on primary scientific literature (Pullin et al. 2004). Furthermore, concern has been raised by Knight et al. (2008, p. 613) that 'the majority of conservation assessments published in the peer reviewed literature were not designed with the intention to implement conservation action', as they found that two-thirds of conservation assessments published do not deliver conservation action. Does this mean that conservation scientists have become desensitized or acclimatized to the fact that their research is not being used? Or is it assumed that publishing means it will be used but not in the short term? Clearly there is room for more open discourse on this topic.

On the other hand, almost half of the respondents believed that lengthy peer-review processes can have consequences for conservation and that this is something that we (the scientific community) can control. If we, as the collective scientific community, can improve the timeliness of the dissemination of important findings, then it is part of winning conservation battles. So what can be done? First, if we presume that the majority of 'important' conservation-oriented work should be published in conservation-oriented journals (e.g. such as those listed under the ISI theme of 'Biodiversity and Conservation'), editorial teams in that realm could make a concerted effort to move towards a 'rapid review' process, meaning giving high priority to these potentially important conservation findings. Doing so takes the collective effort of the entire editorial team beginning with timely paper screening (to make sure the content fits with the journal and is of sufficient quality to disseminate for review), referee selection (and follow-up when they are delinquent) and an editorial decision as soon as possible once reviews are in hand. Similarly, the review community for such journals also needs to take a greater role in recognizing that timeliness matters - that is, all journals in the realm of conservation science need to do so. This argument should not be hard to make considering the basis of the discipline, yet referees also have other pressures related to professional and personal duties. When querying potential referees, it should be made explicit that reviews are needed within a reasonable window (e.g. $15 \mathrm{~d}$, the same window requested by the journals Ecology Letters and Conservation Physiology) and if they are unable to deliver on time then they should not accept the assignment. That is to say, the suite of volunteers - from editors to referees - must all take an active role in helping to provide rapid yet critical and fair assessments of conservation science. This is much easier said than done, as reviewers have other priorities and responsibilities, but investigations into motivations of referees could also be used to produce guidance for best practices in selecting and inviting referees, providing cost-effective incentives and setting time thresholds for various tasks.

When queried about expediting reviews for papers of high policy relevance or conservation implications/ significance, just over one-third of respondents thought that such practice should occur. Yet, in practice, it is unclear how this would happen. Many journals have the capability of expediting time-sensitive reviews, but the process to do so varies per journal and seems unclear. If this task were left to editors to determine which papers were 'most important' at the time of submission, it would imply that they had the ability to do so (i.e. that they are 'oracles', sensu FarjiBrener \& Kitzberger 2014). In reality, editors are not omniscient and although often luminaries in the field, they are unlikely to be able to make such decisions without being alerted by authors that the paper is time-sensitive. Indeed, recent work suggests that editors are poor judges (during initial assessment) as to the future citation patterns of papers (Bornmann \& Daniel 2010, Farji-Brener \& Kitzberger 2014), although that is not the sole reason why papers are rejected without review (Schimel et al. 2014).

One option would be to put the onus on authors to self-identify papers of 'high' conservation relevance or with time-sensitive conservation implications (requiring publication within the next $6 \mathrm{mo}$ ). For example, authors could check a box at the time of submission requesting rapid peer review if they felt that the paper had timely conservation implications and met a suite of criteria (which would need to be clearly defined, and authors would have to make their case) for rapid conservation review. Indeed, some journals (e.g. Science) offer such an option if the finding is of high relevance to conservation or current policy development/discussions. An excerpt from the guide to authors for Science www.science mag.org/authors/science-information-authors states that:

We are able to expedite the review process significantly for papers that require rapid assessment. The framework for expediting reviews is already in place and could be extended for high conservation implications, and while we recognize that placing a priority on one manuscript likely means extending the time required for review of another, our opinion underscores the need for editors to consider what is most important to the scope of their conservation-focused journal. 
We believe in the peer-review process, and from our perspective, we submit that there is a 'need for speed' in peer review, particularly when the matter is time sensitive as indicated by some examples from surveyed authors. A handful of our respondents exposed deeply rooted philosophical beliefs in conservation, and while these are important forms of discourse, it should also be noted that a lack of expertise in policy could create biases due to naïveté. However, this 'need for speed' should not come at the cost of rigorous science and thorough peer review. Although the examples were few, it can be at a great cost if research with significant policy and conservation implications, such as protection of an imperiled species, is missed because of a slow review process - something that as a collective, the scientific community can control. Authors must first build a case for expedited review in their cover letters. Although it would seem unwise to have editors take an even greater role in determining which papers are most policy relevant and assigning them some form of priority in review, authors could take a more active role in doing so by flagging papers that have potentially important findings and in doing so requesting a rapid review. Authors also have the option of choosing journals that offer rapid turnover times and avoid the opportunity cost of the high impact factor obsession (Şekercioğlu 2013). Rushing science (whether it be study design, data collection, analysis or reporting) would seem to be a risky strategy when findings have the potential to influence policy and management despite the fact that some have argued that the entire process needs to be expedited. Until such mechanisms of expediting highly relevant findings are further developed, we make a general plea to the entire publishing community - from editors to referees and beginning with authors - to recognize the urgency within the conservation science discipline and hence the 'need for speed' in peer review of potentially high-impact and timely conservation science. Indeed, an important part of science that is more relevant to conservation practitioners is timeliness (Laurance et al. 2012). Future work on review speed and the mechanics of the peer-review process could further develop the ideas presented here and, if possible, include the sourcing and analysis of actual publication times from journals.

Nonetheless, the fact that over half of the respondents believed a delayed review process is not costly to conservation is also a concern, as it may suggest a number of potential issues such as researchers being accustomed to research not being used or put into practice, researchers avoiding the role of advocacy or their role beyond research (e.g. public engagement, outreach, etc.) or other possibilities (e.g. apathy cynicism) that we have yet to explore. These issues remain part of the knowledge-action or knowingdoing gap that needs to be addressed if we, as conservation practitioners, want to advance conservation and the protection of biodiversity. The notion of 'Doing good, not harm' (Pullin \& Knight 2009) remains a mantra of conservation science and something which must be central to all conservation work.

Acknowledgements. S.J.C. is supported by the Canada Research Chairs Program and NSERC. Thank you to all participants who took part in the online questionnaire. All work was conducted with an ethics clearance from Carleton University.

\section{LITERATURE CITED}

Arlettaz R, Schaub M, Fournier J, Reichlin TS, Sierro A, Watson JEM, Braunisch V (2010) From publications to public actions: when conservation biologists bridge the gap between research and implementation. Bioscience 60:835-842

Bornmann L, Daniel HD (2010) The validity of staff editors' initial evaluations of manuscripts: a case study of Angewandte Chemie International Edition. Scientometrics 85: 681-687

Cook CN, Mascia MB, Schwartz MW, Possingham HP, Fuller RA (2013) Achieving conservation science that bridges the knowledge-action boundary. Conserv Biol 27:669-678

Farji-Brener AG, Kitzberger T (2014) Rejecting editorial rejections revisited: Are editors of ecological journals good oracles? ESA Bull 95:238-242

Gibbons DW, Wilson JD, Green RE (2011) Using conservation science to solve conservation problems. J Appl Ecol 48:505-508

Habel JC, Gossner MM, Meyer ST, Eggermont H, Lens L, Dengler J, Weisser WW (2013) Mind the gaps when using science to address conservation concerns. Biodivers Conserv 22:2413-2427

Hulme PE (2014) Bridging the knowing-doing gap: knowwho, know-what, know-why, know-how and know-when. J Appl Ecol 51:1131-1136

Knight AT, Cowling RM, Rouget M, Balmford A, Lombard AT, Campbell BM (2008) Knowing but not doing: selecting priority conservation areas and the research-implementation gap. Conserv Biol 22:610-617

Laurance WF, Koster H, Grooten M, Anderson AB and others (2012) Making conservation research more relevant for conservation practitioners. Biol Conserv 153:164-168

> McKinley DC, Briggs RD, Bartuska AM (2012) When peerreviewed publications are not enough! Delivering science for natural resource management. For Policy Econ 21:1-11

Meine C, Soulé M, Noss RF (2006) 'A mission-driven discipline': the growth of conservation biology. Conserv Biol 20:631-651

Miles MB, Huberman AM, Saldana J (2014) Qualitative data analysis: a methods sourcebook ( $3^{\text {rd }}$ edn). SAGE Publications, Thousand Oaks, CA 
Nguyen VM, Haddaway NR, Gutowsky LFG, Wilson ADM and others (2015) How long is too long in contemporary peer review? Perspectives from authors publishing in conservation biology journals. PLoS ONE 10:e0132557

O'Donnell RP, Supp SR, Cobbold SM (2010) Hindrance of conservation biology by delays in the submission of manuscripts. Conserv Biol 24:615-620

Pullin AS, Knight TM (2009) Doing more good than harmbuilding an evidence-base for conservation and environmental management. Biol Conserv 142:931-934

Pullin AS, Stewart GB (2006) Guidelines for systematic review in conservation and environmental management. Conserv Biol 20:1647-1656

Pullin AS, Knight TM, Stone DA, Charman K (2004) Do conservation managers use scientific evidence to support

Editorial responsibility: Brendan Godley,

University of Exeter, Cornwall Campus, UK their decision-making? Biol Conserv 119:245-252

Rowland F (2002) The peer-review process. Learn Publ 15: $247-258$

> Schimel D, Strong DR, Ellison AM, Peters DPC and others (2014) Editors are editors, not oracles. Bull Ecol Soc Am 95:342-346

Şekercioğlu CH (2013) Citation opportunity cost of the high impact factor obsession. Curr Biol 23:R701-R702

Soulé ME (1985) What is conservation biology? Bioscience 35:727-734

Tracy CR, Brussard PF (1996) The importance of science in conservation biology. Conserv Biol 10:918-919

Walsh JC, Dicks LV, Sutherland WJ (2015) The effect of scientific evidence on conservation practitioners' management decisions. Conserv Biol 29:88-98

Submitted: June 1, 2015; Accepted: December 23, 2015

Proofs received from author(s): February 9, 2016 